\title{
Castanea sativa Mill. Flowers amongst the Most Powerful Antioxidant Matrices: A Phytochemical Approach in Decoctions and Infusions
}

\author{
Márcio Carocho, ${ }^{1,2}$ Lillian Barros, ${ }^{1}$ Albino Bento, ${ }^{1}$ Celestino Santos-Buelga, ${ }^{3}$ \\ Patricia Morales, ${ }^{2}$ and Isabel C. F. R. Ferreira ${ }^{1}$ \\ ${ }^{1}$ Mountain Research Center (CIMO), ESA, Polytechnic Institute of Bragança, Campus de Santa Apolónia 1172, \\ 5301-855 Bragança, Portugal \\ ${ }^{2}$ Department of Nutrition and Bromatology II, Faculty of Pharmacy, Complutense University of Madrid, Pza Ramón y Cajal, \\ s/n., 28040 Madrid, Spain \\ ${ }^{3}$ Grupo de Investigación en Polifenoles (GIP), Faculty of Pharmacy, University of Salamanca, Campus Miguel de Unamuno, \\ 37007 Salamanca, Spain
}

Correspondence should be addressed to Isabel C. F. R. Ferreira; iferreira@ipb.pt

Received 20 February 2014; Accepted 28 March 2014; Published 14 April 2014

Academic Editor: P. J. Oefner

Copyright (C) 2014 Márcio Carocho et al. This is an open access article distributed under the Creative Commons Attribution License, which permits unrestricted use, distribution, and reproduction in any medium, provided the original work is properly cited.

\begin{abstract}
Infusions and decoction of chestnut tree flowers have been used for different medical purposes, but their phytochemical profile and antioxidant activity are still mostly unknown. Herein, decoctions and infusions of flowers from the two most appreciated chestnut cultivars (longal and judia) in Trás-os-Montes, Portugal, were prepared and characterized with regard to their content in free sugars, organic acids, and phenolic compounds, such as flavonoids and hydrolyzable tannins, and their antioxidant activity. Overall, the decoction of the cultivar judia was the sample with both the highest quantity of flavonoids and antioxidant activity. The phenolic compound with the highest abundance in all samples was trigalloyl-HHDP-glucoside, followed by pentagalloyl glucoside. The sample with the highest quantity of total phenolic compounds was judia infusion, closely followed by longal decoction, which also gave the highest quantities of ellagitannins. Regarding sugars and organic acids, the profiles were more similar. These results corroborate ancestral claims of the health benefits of infusions and decoctions of chestnut flowers.
\end{abstract}

\section{Introduction}

In the Trás-os-Montes region of Portugal and across a good part of the Mediterranean countries, chestnut trees are a considerable part of the landscape. These trees and their respective nuts have been important in the past and are still a source of income for those regions. In Portugal, chestnuts are almost totally exported, translating into a revenue of 32 million euros in $2012[1,2]$. The chestnut tree has a variety of applications; the nuts are used for human and animal feed, being widely appreciated and even transformed into many typical dishes and desserts. The wood is used for high class furniture. The leaves are used in many ethnobotanic formulations against colds, coughs, diarrhea, and even high blood cholesterol [3]. Furthermore, some patents indicate the use of chestnut flowers in beverages like teas and refreshments [4$6]$.

The nutritional and bioactive properties of the fruits and flowers of chestnuts have been reported [7-9]. Barros et al. $[8,9]$ described the high antioxidant potential and phenolic compounds profile of methanolic extracts obtained from the flowers. In fact, some of the most antioxidant molecules are not always found in fruits, but in richer polyphenolic matrices like flowers. Other antioxidant molecules include some organic acids that among many other beneficial activities are known to act against free radicals $[8,10]$.

The characterization of antioxidant molecules present in flowers is fundamental to draw conclusions concerning their antioxidant potential, which could be interesting for the food industry, by adding antioxidant extracts to foodstuffs or using 
them in coatings, in order to extend their shelf-life and reduce consumption of chemical additives [11].

In this report, the decoctions and infusions of flowers from the two most appreciated chestnut cultivars (longal and judia) from Trás-os-Montes, Portugal, were characterized regarding their content of hydrophilic antioxidant molecules (free sugars, organic acids, and phenolic compounds), reducing power, free radicals scavenging activity, and lipid peroxidation inhibition.

\section{Materials and Methods}

2.1. Standards and Reagents. Acetonitrile 99.9\%, of high performance liquid chromatography (HPLC) grade, and sulphuric acid were acquired from Fisher Scientific (Lisbon, Portugal). Formic acid was acquired from Panreac (Barcelona, Spain). Sugar standards [D(-)-fructose, D(+)glucose anhydrous and $\mathrm{D}(+)$-sucrose], organic acid standards (malic acid, shikinic acid; oxalic acid and quinic acid), and trolox (6-hydroxy-2,5,7,8-tetramethylchroman-2-carboxylic acid) were acquired from Sigma Chemical Co. (Saint Louis, MO, USA). Phenolic compound standards (catechin, gallic acid, isorhamnetin 3-O-glucoside, kaempferol 3-O-glucoside, kaempferol 3-O-rutinoside, myricetin, quercetin 3-O-glucoside and quercetin 3-O-rutinoside) were purchased from Extrasynthese (Genay, France). 2,2-Diphenyl-1-picrylhydrazyl (DPPH) was obtained from Alfa Aesar (Ward Hill, MA, USA). Water was treated by means of a Milli-Q water purification system (TGI Pure Water Systems, Greenville, SC, USA).

2.2. Flower Samples. Castanea sativa Mill. flowers of the cultivars judia and longal were collected in June 2013 in Oleiros, Bragança (north-eastern Portugal) $\left(41^{\circ} 51^{\prime} 02^{\prime \prime} \mathrm{N}, 6^{\circ} 49^{\prime} 54^{\prime \prime} \mathrm{W}\right)$. The specimens were lyophilized (FreeZone 4.5, Labconco, Kansas, USA), milled down to a fine powder, and finally stored at $-5^{\circ} \mathrm{C}$ until analysis.

2.3. Preparation of the Decoctions and Infusions. For the infusions preparation, the lyophilized flowers $(1 \mathrm{~g})$ were added to $200 \mathrm{~mL}$ of boiling distilled water, left to stand for $5 \mathrm{~min}$, and finally filtered through a Whatman filter paper. The obtained infusions were frozen and lyophilized.

For the decoctions preparation, the lyophilized flowers $(1 \mathrm{~g})$ were added to $200 \mathrm{~mL}$ of boiling distilled water, boiled for $5 \mathrm{~min}$, and then left to stand at room temperature for 5 more minutes. After filtration through a Whatman filter paper, the obtained decoctions were frozen and lyophilized.

2.4. Analysis of Free Sugars. Free sugars were determined by HPLC coupled to a refraction index (RI) detector as described previously [8]. The equipment consisted of a pump (Knauer, Smartline System 1000, Berlin, Germany), a degasser (Smartline Manager 5000), an autosampler (AS-2057 Jasco, Easton, MD, USA), and a RI detector (Knauer Smartline 2300). The identification was achieved by comparing the relative retention times of sample peaks with standards. Quantification was made by the internal standard method, and the results are expressed in mg per $g$ of lyophilized decoction or infusion.
2.5. Analysis of Organic Acids. Organic acids were determined following a procedure previously optimized and described by the authors [10]. Analysis was performed on a Shimadzu 20A series ultra-fast liquid chromatograph (UFLC, Shimadzu Cooperation, Kyoto, Japan) coupled to photodiode array detector (PDA, Shimadzu), using $215 \mathrm{~nm}$ and $245 \mathrm{~nm}$ as the preferred wavelengths. Separation was achieved on a SphereClone (Phenomenex, Torrance, CA, USA) reverse phase C18 column $(5 \mu \mathrm{m}, 250 \mathrm{~mm} \times 4.6 \mathrm{~mm}$ i.d) thermostatted at $35^{\circ} \mathrm{C}$. Analytes were eluted with $3.6 \mathrm{mM}$ sulphuric acid at a flow-rate of $0.8 \mathrm{~mL} / \mathrm{min}$. The organic acids found were quantified by comparison of the area of their peaks recorded at $215 \mathrm{~nm}$ or $245 \mathrm{~nm}$ (for ascorbic acid) with calibration curves obtained from commercial standards of each compound: oxalic acid $\left(y=1 x 107 x+96178 ; R^{2}=\right.$ $0.999)$; quinic acid ( $\left.y=601768 x+8853.2 ; R^{2}=1\right)$; malic acid $\left(y=952269 x+17803 ; R^{2}=1\right)$; shikimic acid $(y=$ $\left.8 \times 107+55079 ; R^{2}=0.999\right)$. The results were expressed in $\mathrm{mg}$ per $g$ of lyophilized decoction or infusion.

2.6. Analysis of Phenolic Compounds. Phenolic compounds were determined by HPLC (Hewlett-Packard 1100, Agilent Technologies, Santa Clara, CA, USA) as previously described [9]. Double online detection was carried out with a PDA using $280 \mathrm{~nm}$ and $370 \mathrm{~nm}$ as the preferred wavelengths and a mass spectrometer (MS) connected to the HPLC system via the PDA cell outlet. Mass spectrometric detection was performed by means of an API 3200 (Applied Biosystems, Darmstadt, Germany) triple quadrupole-ion trap analyser equipped with an ESI source. Spectra were recorded in negative ion mode between $\mathrm{m} / z 100$ and 1700. The phenolic compounds were characterized according to their UV, mass spectra, retention times, and comparison with authentic standards when available. For the quantitative analysis of phenolic compounds, a baseline to valley integration with baseline projection mode was used to calculate peak areas. For quantification, calibration curves were generated by injection of known concentration $(2.5-100 \mu \mathrm{g} / \mathrm{mL})$ of standard compounds: catechin $\left(y=132.76 x-59.658 ; R^{2}=1\right)$; gallic acid ( $\left.y=556.94 x-738.37 ; R^{2}=0.999\right)$; isorhamnetin3-O-glucoside ( $\left.y=262.31 x-9.8958 ; R^{2}=1\right)$; kaempferol-3$O$-glucoside $\left(y=190.75 x-36.158 ; R^{2}=1\right)$; kaempferol-3$O$-rutinoside $\left(y=175.02 x-43.877 ; R^{2}=0.999\right)$; myricetin $\left(y=778 x-1454.3 ; R^{2}=0.999\right)$; quercetin-3-O-glucoside $\left(y=316.48 x-2.9142 ; R^{2}=1.000\right)$; and quercetin-3$O$-rutinoside $\left(y=222.79 x-243.11 ; R^{2}=0.999\right)$. The results were expressed in $\mathrm{mg}$ per $\mathrm{g}$ of lyophilized decoction or infusion.

2.7. Evaluation of Antioxidant Activity. The in vitro antioxidant activity assays were performed following the previously described methodology of Barros et al. [8]. The lyophilized infusions and decoctions were dissolved in water (final concentration $10 \mathrm{mg} / \mathrm{mL}$ ); the final solution was further diluted to different concentrations to be used in the following assays. DPPH radical-scavenging activity was evaluated using an ELX800 microplate Reader (Bio-Tek Instruments, Inc.; Winooski, VT, USA) and calculated as a percentage of DPPH 


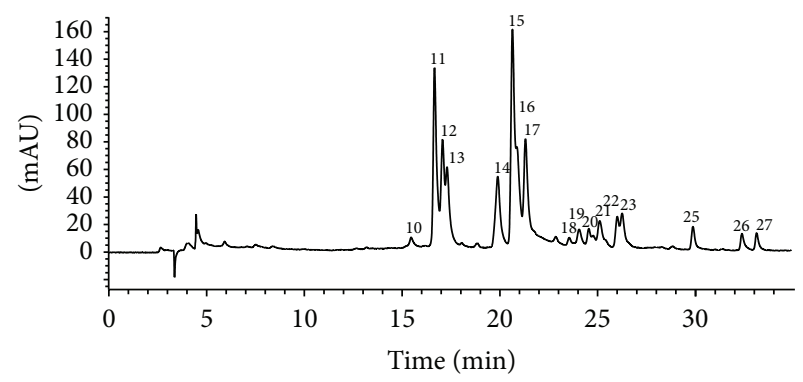

(a)

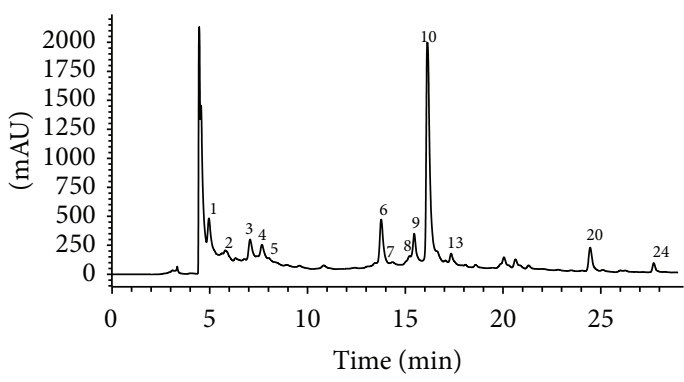

(b)

FIGURE 1: Phenolic profile of the infusion of Castanea sativa flowers (judia cultivar) recorded at $370 \mathrm{~nm}$ (a) and $280 \mathrm{~nm}$ (b).

discolouration after 1 hour of incubation with the antioxidant extract, using the formula: $\left[\left(A_{\mathrm{DPPH}}-A_{S}\right) / A_{\mathrm{DPPH}}\right] \times 100$, where $A_{S}$ is the absorbance of the solution containing the sample at $515 \mathrm{~nm}$, and $A_{\mathrm{DPPH}}$ is the absorbance of the DPPH solution. Reducing power was evaluated by the capacity to reduce $\mathrm{Fe}^{3+}$ into $\mathrm{Fe}^{2+}$, measuring the absorbance at $690 \mathrm{~nm}$ in the microplate reader mentioned. Inhibition of $\beta$-carotene bleaching was evaluated through the $\beta$-carotene/linoleate assay; the neutralization of linoleate free radicals avoids $\beta$ carotene bleaching, which is measured by the formula: $(\beta$ carotene absorbance after $2 \mathrm{~h}$ of assay/initial absorbance) $\times$ 100. Lipid peroxidation inhibition in porcine (Sus scrofa) brain homogenates was evaluated by the decrease in thiobarbituric acid reactive substances (TBARS); the colour intensity of the malondialdehyde-thiobarbituric acid (MDA-TBA) was measured by its absorbance at $532 \mathrm{~nm}$; the inhibition ratio (\%) was calculated using the following formula: $[(A-B) / A] \times$ $100 \%$, where $A$ and $B$ were the absorbance of the control and the sample solution, respectively. The results of the antioxidant activity were expressed in $\mathrm{EC}_{50}$ value (sample concentration providing $50 \%$ of antioxidant activity or 0.5 of absorbance in the reducing power assay).

2.8. Statistical Analysis. All the assays were carried out in triplicate for both decoctions and infusions of each cultivar. The results are expressed as mean values \pm standard deviations (SD). The statistical differences represented by letters were obtained through one-way analysis of variance (ANOVA) followed by Tukey's honestly significant difference post hoc test with $\alpha=0.05$. Statistical analyses were carried out using the SPSS v. 18.0 program.

\section{Results and Discussion}

3.1. Analysis of Free Sugars and Organic Acids. Three free sugars, namely, fructose, glucose, and sucrose, were detected in all the samples (Table 1). Sucrose was the least abundant sugar, while fructose and glucose were the most abundant in the cultivars judia and longal, respectively. This had been also reported for methanolic extracts of C. sativa flowers [9]. Glucose and fructose were present at higher levels in decoctions than infusions, probably due to the longer extraction time, albeit significant differences were only found in the case of the cultivar longal. By contrast, higher concentrations of sucrose were extracted in the infusions, although the increase was only statistically significant in the case of judia. No significant differences were observed among samples.

Oxalic, quinic, malic, and shikimic acids were quantified in all the samples, with quinic acid being the most abundant acid (Table 1). Decoctions generally yielded higher quantities of oxalic acid in comparison to infusions, and statistical differences for this compound were only noted for the infusion of longal. The longal cultivar did not display statistical differences for quinic acid in both extraction methods, but for judia statistical differences were found between extraction methods. Malic acid and shikimic acid displayed similar concentrations in all the samples, whereas some differences were found among samples regarding quinic acid. The decoction of judia displayed the highest concentrations of total organic acids of the samples analysed.

3.2. Analysis of Phenolic Compounds. An exemplary phenolic profile of the judia cultivar of C. sativa recorded at $280 \mathrm{~nm}$ and $370 \mathrm{~nm}$ is shown in Figure 1. Twenty-seven phenolic compounds were identified in both judia and longal cultivars (infusion and decoction preparations). Peak characteristics and tentative identities are presented in Table 2.

Peaks 1-4, 6-10,13,20, 24, and 25 showed UV spectra coherent with galloyl and hexahydroxydiphenoyl (HHDP) derivatives [12-14]. According to the literature, the main characteristic in the mass spectra of these compounds is the deprotonated molecule $[\mathrm{M}-\mathrm{H}]^{-}$and the loss of one or more ellagic acid $(302 \mathrm{mu})$, gallic acid $(170 \mathrm{mu})$, and/or galloyl groups (152 mu) $[12,15,16]$. Peaks 1 and 2 presented a singly charged pseudomolecular ion $[\mathrm{M}-\mathrm{H}]^{-}$at $\mathrm{m} / z 783$ and daughter ions at $m / z 481$ and 301, which together with their early elution allowed their identification as pedunculagin (i.e., bis-HHDP-glucose) isomers [17]. Mass characteristics of peak $3\left([\mathrm{M}-\mathrm{H}]^{-}\right.$at $\mathrm{m} / z$ 633; fragment ions at $\mathrm{m} / \mathrm{z} 463$ and 301) coincided with a galloyl-HHDP-glucose isomer $[16,17]$, whereas peaks 4,10 , and $13\left([\mathrm{M}-\mathrm{H}]^{-}\right.$at $\mathrm{m} / \mathrm{z} 937$; fragment ions at $m / z 767,637,467$ and 301) were coherent with trigalloyl-HHDP-glucose isomers [13], already reported in C. sativa heartwood [18] and flowers [9]. Peak 6 presented a pseudomolecular ion $[\mathrm{M}-\mathrm{H}]^{-}$at $m / z$ 939, yielding $\mathrm{MS}^{2}$ fragment ions at $m / z 631$ [M-2galloyl-3H] $]^{-}, 469$ [M-2galloyl$3 \mathrm{H}$-glu $]^{-}$, being identified as pentagalloylglucose. Peak 7 with a pseudomolecular ion $[\mathrm{M}-\mathrm{H}]^{-}$at $\mathrm{m} / z 935$ and $\mathrm{MS}^{2}$ product ions at $\mathrm{m} / z 633$ and 301, likely due to the loss of HHDP and galloyl-glucose moieties, was consistent with a galloyl- 
TABLE 1: Content of free sugars and organic acids in $\mathrm{mg} / \mathrm{g}$ of lyophilized decoction/infusion of the flowers of two Castanea sativa cultivars.

\begin{tabular}{|c|c|c|c|c|}
\hline & Decoction judia & Decoction longal & Infusion judia & Infusion longal \\
\hline \multicolumn{5}{|l|}{ Sugars } \\
\hline Fructose & $160.41 \pm 0.01^{\mathrm{a}}$ & $152.08 \pm 6.52^{\mathrm{a}}$ & $148.94 \pm 4.60^{\mathrm{a}}$ & $123.58 \pm 1.76^{\mathrm{b}}$ \\
\hline Glucose & $149.09 \pm 0.04^{\mathrm{b}}$ & $191.91 \pm 7.35^{\mathrm{a}}$ & $145.71 \pm 5.63^{\mathrm{b}}$ & $164.07 \pm 2.31^{\mathrm{b}}$ \\
\hline Sucrose & $27.01 \pm 0.45^{\mathrm{b}}$ & $25.69 \pm 0.99^{\mathrm{b}}$ & $35.68 \pm 1.45^{\mathrm{a}}$ & $26.67 \pm 0.50^{\mathrm{b}}$ \\
\hline Total & $336.51 \pm 0.48^{\mathrm{a}}$ & $369.69 \pm 14.85^{\mathrm{a}}$ & $330.32 \pm 11.69^{\mathrm{a}}$ & $314.32 \pm 4.57^{\mathrm{a}}$ \\
\hline \multicolumn{5}{|l|}{ Organic Acids } \\
\hline Oxalic acid & $72.91 \pm 1.82^{\mathrm{a}}$ & $71.85 \pm 0.52^{\mathrm{ab}}$ & $43.42 \pm 0.75^{\mathrm{c}}$ & $55.84 \pm 1.82^{\mathrm{bc}}$ \\
\hline Quinic acid & $84.61 \pm 0.64^{\mathrm{a}}$ & $52.59 \pm 3.14^{\mathrm{b}}$ & $69.04 \pm 2.81^{\mathrm{ab}}$ & $61.63 \pm 4.40^{\mathrm{b}}$ \\
\hline Malic acid & $27.17 \pm 1.36^{\mathrm{a}}$ & $22.94 \pm 0.10^{\mathrm{a}}$ & $25.03 \pm 0.52^{\mathrm{a}}$ & $20.82 \pm 0.70^{\mathrm{a}}$ \\
\hline Shikimic acid & $1.83 \pm 0.02^{\mathrm{a}}$ & $1.26 \pm 0.08^{\mathrm{a}}$ & $1.35 \pm 0.02^{\mathrm{a}}$ & $1.35 \pm 0.07^{\mathrm{a}}$ \\
\hline Total & $186.52 \pm 3.84^{\mathrm{a}}$ & $148.65 \pm 2.79^{\mathrm{ab}}$ & $138.83 \pm 2.61^{\mathrm{b}}$ & $139.64 \pm 6.99^{b}$ \\
\hline
\end{tabular}

In each row different letters mean significant differences with a $P<0.05$. Letters refer to Tukey's post hoc test; therefore, significant different values were classified using letters in alphabetic order.

TABLE 2: Retention time (Rt), wavelength of maximum absorption $\left(\lambda_{\max }\right)$, mass spectral data, and tentative identification of phenolic compounds in decoctions and infusions of Castanea sativa flowers.

\begin{tabular}{|c|c|c|c|c|c|}
\hline Peak & Rt (min) & $\begin{array}{l}\lambda_{\max } \\
(\mathrm{nm})\end{array}$ & $\begin{array}{l}\text { Pseudomolecular } \\
\text { ion }[\mathrm{M}-\mathrm{H}]^{-}(\mathrm{m} / z)\end{array}$ & $\begin{array}{c}\mathrm{MS}^{2}(\mathrm{~m} / z) \\
(\% \text { of base peak) }\end{array}$ & Tentative identification \\
\hline 1 & 4.96 & 276 & 783 & $481(10), 301(41)$ & Pedunculagin isomer (bis-HHDP-glucose) \\
\hline 2 & 5.79 & 268 & 783 & $481(6), 301(45)$ & Pedunculagin isomer (bis-HHDP-glucose) \\
\hline 3 & 7.06 & 272 & 633 & $463(17), 301(100)$ & Galloyl-HHDP-glucose \\
\hline 4 & 7.67 & 274 & 937 & 637 (15), 467 (2), $301(4)$ & Trigalloyl-HHDP-glucose \\
\hline 5 & 8.02 & 278 & 289 & $245(91), 203(60), 137(38)$ & $(+)$-Catechin \\
\hline 6 & 13.77 & 276 & 939 & $631(31), 469(66), 169(100)$ & Pentagalloyl glucose \\
\hline 7 & 14.92 & 276 & 935 & $633(15), 301(18)$ & Galloyl-bis-HHDP-glucose \\
\hline 8 & 15.25 & 274 & 933 & $\begin{array}{c}915(5), 633(8), 451(24) \\
301(7)\end{array}$ & Castalagin/vescalagin \\
\hline 9 & 15.46 & 278 & 907 & $\begin{array}{c}767(3), 607(24), 467(35) \\
169(5)\end{array}$ & Galloyl-HHDP derivative \\
\hline 10 & 16.13 & 274 & 937 & $\begin{array}{c}767(2), 637(8), 467(68) \\
301(10)\end{array}$ & Trigalloyl-HHDP-glucoside \\
\hline 11 & 16.65 & 358 & 493 & $317(100)$ & Myricetin $O$-glucuronide \\
\hline 12 & 17.07 & 350 & 479 & $317(100)$ & Myricetin 3-O-glucoside \\
\hline 13 & 17.30 & 274 & 937 & $\begin{array}{c}767(2), 637(5), 467(58) \\
301(7)\end{array}$ & Trigalloyl-HHDP-glucoside \\
\hline 14 & 19.89 & 356 & 609 & $301(100)$ & Quecetin 3-O-rutinoside \\
\hline 15 & 20.64 & 356 & 477 & $301(100)$ & Quercetin 3-O-glucuronide \\
\hline 16 & 20.86 & 356 & 463 & $301(100)$ & Quercetin 3-O-glucoside \\
\hline 17 & 21.30 & 356 & 463 & $301(100)$ & Quercetin O-hexoside \\
\hline 18 & 23.54 & 350 & 593 & $285(100)$ & Kaempferol 3-O-rutinoside \\
\hline 19 & 24.05 & 354 & 433 & $301(100)$ & Quercetin O-pentoside \\
\hline 20 & 24.46 & 268 & 907 & $\begin{array}{c}767(3), 607(23), 467(67) \\
169(7)\end{array}$ & Galloyl-HHDP derivative \\
\hline 21 & 25.11 & 348 & 477 & $285(100)$ & Kaempferol 3-O-glucoside \\
\hline 22 & 26.00 & 354 & 477 & $315(100)$ & Isorhamnetin $O$-hexoside \\
\hline 23 & 26.25 & 354 & 491 & $315(100)$ & Isorhamnetin $O$-glucuronide \\
\hline 24 & 27.71 & 274 & 907 & $\begin{array}{c}767(2), 607(27), 467(76) \\
169(8)\end{array}$ & Galloyl-HHDP derivative \\
\hline 25 & 29.87 & $250 / 368$ & 343 & 328 (97), 313 (100), 298 (36) & Tri-O-methylellagic acid \\
\hline 26 & 32.38 & 358 & 609 & $463(76), 301(40)$ & Quercetin O-rhamnosyl hexoside \\
\hline 27 & 33.13 & 356 & 519 & 477 (5), $315(77)$ & Isorhamnetin $O$-acetylhexoside \\
\hline
\end{tabular}


bis-HHDP-glucose isomer $[15,17,19]$. Pseudomolecular ion $\left([\mathrm{M}-\mathrm{H}]^{-}\right.$at $m / z$ 933) and fragmentation pattern (ions at $\mathrm{m} / z 915,631,451$ and 301) of peak 8 were in agreement with those attributed to castalagin or vescalagin isomers $[17,20]$, already reported in C. sativa heartwood [18]. Peaks 9 , 20, and 24 are most likely galloyl-HHDP derivatives, with an unusual parent ion $[\mathrm{M}-\mathrm{H}]^{-}$at $\mathrm{m} / z$ 907, but with characteristic fragments of this type of compounds $(\mathrm{m} / z$ at 767, 467 and 169). No structure could be assigned to these peaks that remain unidentified. A fragment ion with $\mathrm{m} / z$ at 907 was reported as released from the cleavage of a di(HHDPgalloylglucose)-pentose found in pomegranate juice [21] and from unknown ellagitannins present in blackberries [17]. Peak 25 presented an ellagic acid-like UV spectrum $\left(\lambda_{\max }\right.$ around 250 and $368 \mathrm{~nm}$ ) and a pseudo molecular ion [M$\mathrm{H}]^{-}$at $m / z 343$, releasing three fragments at $m / z 328$, 313 and $298 \mathrm{mu}$, corresponding to the successive losses of three methyl groups $(-15 \mathrm{mu})$, which allowed its tentative identification as a tri-O-methylellagic acid.

Regarding flavonoids, flavonol derivatives were the main compounds found in the analyzed samples (Table 2). Catechin (peak 5), myricetin 3-O-glucoside (peak 12), quercetin 3-O-rutinoside (peak 14), quercetin 3-O-glucoside (peak 16), kaempferol 3-O-rutinoside (peak 18), and kaempferol 3-Oglucoside (peak 21) were positively identified according to their retention, mass, and UV-vis characteristics by comparison with commercial standards. Peak 11 was assigned to a myricetin $O$-glucuronide, according to the pseudomolecular ion $[\mathrm{M}-\mathrm{H}]^{-}$at $m / z 497$ and $\mathrm{MS}^{2}$ fragment released at $m / z 317$ ([M-H-176] $]^{-}$, loss of glucuronyl moiety). Peaks 15, 17, 19, and 26 presented UV spectra with $\lambda_{\text {max }}$ around $350 \mathrm{~nm}$ and an $\mathrm{MS}^{2}$ product ion at $\mathrm{m} / z 301$ indicating that they correspond to quercetin derivatives. According to their pseudomolecular ions, they were identified as quercetin 3-O-glucuronide (peak 15 ; [M-H] $]^{-}$at $m / z 477$ ), which was confirmed by comparison with a standard obtained in our laboratory [22], quercetin $O$-hexoside (peak 17; $[\mathrm{M}-\mathrm{H}]^{-}$at $\mathrm{m} / z$ 463), quercetin $O$ pentoside (peak 19; $[\mathrm{M}-\mathrm{H}]^{-}$at $\mathrm{m} / z$ 433), and quercetin $O$ rhamnosyl hexoside (peak 26; $[\mathrm{M}-\mathrm{H}]^{-}$at $\mathrm{m} / z$ 609). Similarly reasoning also allowed assigning peaks 22 and 23 as isorhamnetin $O$-hexoside and isorhamnetin $O$-glucuronide, respectively. Peak 27 should correspond to isorhamnetin $O$ acetylhexoside according to the pseudomolecular ion [M$\mathrm{H}]^{-}$at $m / z 519$ and $\mathrm{MS}^{2}$ fragment released at $m / z 315$ ([MH-42-162 $]^{-}$, loss of an acetylhexoside moiety). The individual polyphenol with the highest concentration in all samples was a trigalloyl-HHDP-glucoside (peak 10), followed by pentagalloyl glucose (peak 6), whereas quercetin 3-O-glucuronide (peak 15) and a quercetin hexoside (peak 17) were the most abundant flavonoids in judia and longal cultivars, respectively (Table 3). The sample with the highest concentration of total polyphenols was the infusion of judia, closely followed by the decoction of longal. The preparations of the cultivar judia presented higher flavonoid levels, while those of longal displayed higher concentrations of hydrolyzable tannins (Table 3 ). The compounds present in the samples were, to some extent, different from those found in a $C$. sativa hydromethanolic extract [9]. Nevertheless, the main ellagitannins found in this study were in accordance with the mentioned study.
3.3. Antioxidant Activity. The antioxidant activity of the C. sativa samples was determined through various assays, namely, DPPH scavenging activity, reducing power through Prussian-blue assay, inhibition of $\beta$-carotene bleaching, and finally inhibition of TBARS formation in brain cell homogenates (Table 4). Decoctions showed greater antioxidant activity than infusions; this might be explained by the longer time at boiling point that decoctions were subjected to during extraction. In terms of scavenging of DPPH radicals, statistically significant differences were found between decoctions and infusions. Reducing power, $\beta$-carotene bleaching inhibition and TBARS assays gave statistically significant different results among samples, but the lowest $\mathrm{EC}_{50}$ values were always obtained in the TBARS assay, this could be due to its specificity, sensibility, and low quantity of interferences.

This assay was the only one that reported lower $\mathrm{EC}_{50}$ values for infusions, which can be related to the low heat resistance of antioxidants that inhibit lipid peroxidation, like tocopherols and other vitamins [23].

Among the four samples, the decoction of judia proved to be the most antioxidant among the samples analysed. This could be explained by antioxidant variability of cultivars, translating into a higher antioxidant potential of judia when compared to longal. Further research should be carried out to determine what antioxidants apart from phenolic compounds are present in these flowers that could help clarify this antioxidant variability between cultivars. Nevertheless, in general, all the studied samples proved to be powerful antioxidants when compared to other herbal matrices previously studied by the authors $[8,9]$.

\section{Conclusion}

The ancestral claims of health benefits of chestnuts flowers were partially corroborated in this paper. The organic acids could be responsible for some antioxidant potential, but further research can be carried out in terms on tocopherols and other vitamins and minerals that could provide more insight into the total amount of antioxidants. Further research should be carried out on the potentiality of these flowers in the pharmaceutical and food industries, among others. Pharmaceutical industries could use the flowers as excipients for dietary supplements, benefiting from their natural content in polyphenols for health purposes. The food industry, which has recently started to intensify its search for natural conservatives and additives, to add to transformed foodstuffs, meeting the consumers habits, can use the high antioxidant power and natural high abundance of tannins in the flowers to preserve food and inhibit lipid deterioration and microorganism development. Although quite beneficial, the flowers used for these purposes should not be picked from the tree, but rather from the ground to avoid interference of pollination. Methanolic extractions have also been performed for chestnut flowers and yielded good results $[8,9]$, although the usage of methanol is not recommended in the food industry; but on the other hand, extractions with this solvent could carry hydrophobic antioxidant compounds. 
TABLE 3: Quantification of phenolic compounds in infusions and decoctions of Castanea sativa flowers expressed in mg/g of lyophilized decoction/infusion.

\begin{tabular}{|c|c|c|c|c|}
\hline Compounds & Decoction judia & Decoction longal & Infusion judia & Infusion longal \\
\hline Pedunculagin isomer (bis-HHDP-glucose) & $5.21 \pm 0.11$ & $8.48 \pm 0.51$ & $5.98 \pm 0.16$ & $7.68 \pm 0.11$ \\
\hline Pedunculagin isomer (bis-HHDP-glucose) & $1.12 \pm 0.09$ & $1.44 \pm 0.19$ & $0.92 \pm 0.92$ & $1.21 \pm 0.04$ \\
\hline Galloyl-HHDP-glucose & $3.07 \pm 0.14$ & $3.18 \pm 0.00$ & $3.18 \pm 0.07$ & $3.05 \pm 0.09$ \\
\hline Trigalloyl-HHDP-glucose & $2.81 \pm 0.25$ & $5.51 \pm 0.06$ & $2.60 \pm 0.06$ & $4.30 \pm 0.47$ \\
\hline$(+)$-Catechin & $1.14 \pm 0.12$ & $1.58 \pm 0.14$ & $1.11 \pm 0.03$ & $1.10 \pm 0.05$ \\
\hline Pentagalloyl glucose & $5.61 \pm 0.08$ & $6.04 \pm 0.15$ & $5.73 \pm 0.14$ & $6.47 \pm 0.15$ \\
\hline Galloyl-bis-HHDP-glucose & $0.45 \pm 0.04$ & $0.29 \pm 0.07$ & $0.66 \pm 0.01$ & $0.30 \pm 0.01$ \\
\hline Castalagin/vescalagin & $0.75 \pm 0.06$ & $0.73 \pm 0.11$ & $1.06 \pm 0.09$ & $1.61 \pm 0.04$ \\
\hline Galloyl-HHDP derivative & $0.38 \pm 0.02$ & $0.55 \pm 0.07$ & $3.60 \pm 0.16$ & $3.72 \pm 0.01$ \\
\hline Trigalloyl-HHDP-glucoside & $26.72 \pm 0.15$ & $28.16 \pm 0.11$ & $30.70 \pm 0.40$ & $28.73 \pm 1.34$ \\
\hline Myricetin $O$-glucuronide & $1.13 \pm 0.02$ & $0.09 \pm 0.00$ & $0.96 \pm 0.01$ & $0.08 \pm 0.00$ \\
\hline Myricetin 3-O-glucoside & $0.66 \pm 0.01$ & $0.09 \pm 0.01$ & $0.60 \pm 0.01$ & $0.09 \pm 0.00$ \\
\hline Trigalloyl-HHDP-glucoside & $1.33 \pm 0.00$ & $0.54 \pm 0.01$ & $1.61 \pm 0.05$ & $0.70 \pm 0.04$ \\
\hline Quecetin 3-O-rutinoside & $1.57 \pm 0.01$ & $0.52 \pm 0.03$ & $1.31 \pm 0.10$ & $0.48 \pm 0.05$ \\
\hline Quercetin 3-O-glucuronide & $3.55 \pm 0.10$ & $1.56 \pm 0.04$ & $3.38 \pm 0.01$ & $1.49 \pm 0.07$ \\
\hline Quercetin 3-O-glucoside* & $1.80 \pm 0.01$ & $0.89 \pm 0.02$ & $1.60 \pm 0.04$ & $0.91 \pm 0.10$ \\
\hline Quercetin $O$-hexoside & $2.21 \pm 0.07$ & $1.82 \pm 0.05$ & $2.11 \pm 0.02$ & $1.85 \pm 0.06$ \\
\hline Kaempferol 3-O-rutinoside & $0.21 \pm 0.01$ & $0.21 \pm 0.03$ & $0.18 \pm 0.01$ & $0.21 \pm 0.01$ \\
\hline Quercetin $O$-pentoside & $0.43 \pm 0.02$ & $0.20 \pm 0.01$ & $0.34 \pm 0.00$ & $0.22 \pm 0.02$ \\
\hline Galloyl-HHDP derivative & $4.18 \pm 0.10$ & $4.54 \pm 0.14$ & $2.41 \pm 0.14$ & $1.96 \pm 0.12$ \\
\hline Kaempferol 3-O-glucoside & $0.53 \pm 0.00$ & $0.49 \pm 0.01$ & $0.41 \pm 0.00$ & $0.46 \pm 0.04$ \\
\hline Isorhamnetin $O$-hexoside & $0.33 \pm 0.04$ & $0.27 \pm 0.01$ & $0.27 \pm 0.00$ & $0.30 \pm 0.01$ \\
\hline Isorhamnetin $O$-glucuronide & $0.35 \pm 0.03$ & $0.50 \pm 0.02$ & $0.33 \pm 0.01$ & $0.46 \pm 0.04$ \\
\hline Galloyl-HHDP derivative & $2.04 \pm 0.06$ & $2.02 \pm 0.03$ & $0.72 \pm 0.01$ & $0.59 \pm 0.01$ \\
\hline Tri-O-methylellagic acid & $0.10 \pm 0.01$ & $\operatorname{tr}$ & $0.08 \pm 0.01$ & $\operatorname{tr}$ \\
\hline Quercetin O-rhamnosyl hexoside & $0.23 \pm 0.00$ & $0.10 \pm 0.01$ & $0.23 \pm 0.03$ & $0.09 \pm 0.00$ \\
\hline Isorhamnetin $O$-acetylhexoside & $0.11 \pm 0.00$ & $0.08 \pm 0.01$ & $0.12 \pm 0.01$ & $0.04 \pm 0.00$ \\
\hline Total flavonoids & $14.26 \pm 0.14^{\mathrm{a}}$ & $8.38 \pm 0.01^{\mathrm{c}}$ & $12.94 \pm 0.17^{\mathrm{b}}$ & $7.79 \pm 0.35^{\mathrm{d}}$ \\
\hline Total hydrolyzable tannins & $53.78 \pm 0.31^{\mathrm{c}}$ & $61.49 \pm 0.80^{\mathrm{a}}$ & $59.25 \pm 0.03^{\mathrm{b}}$ & $60.32 \pm 1.87^{\mathrm{ab}}$ \\
\hline Total phenolic compounds & $68.04 \pm 0.18^{c}$ & $69.88 \pm 0.81^{b c}$ & $72.20 \pm 0.14^{\mathrm{a}}$ & $68.10 \pm 1.52^{c}$ \\
\hline
\end{tabular}

In each row different letters mean significant differences with a $P<0.05$. They refer to Tukey's post hoc test; therefore, significant different values were classified using letters in alphabetic order. tr: compound detected in trace amount. ${ }^{*}$ Estimation due to its low resolution.

TABLE 4: Antioxidant activity of decoctions and infusions of the flowers of two Castanea sativa cultivars.

\begin{tabular}{|c|c|c|c|c|}
\hline $\begin{array}{l}\text { Antioxidant activity } \\
\left(\mathrm{EC}_{50} \text { values, } \mu \mathrm{g} / \mathrm{mL}\right)\end{array}$ & Decoction judia & Decoction longal & Infusion judia & Infusion longal \\
\hline $\begin{array}{l}\text { DPPH scavenging } \\
\text { activity }\end{array}$ & $99.47 \pm 0.006^{\mathrm{b}}$ & $100.04 \pm 0.01^{\mathrm{b}}$ & $126.61 \pm 0.005^{\mathrm{a}}$ & $133.56 \pm 0.005^{\mathrm{a}}$ \\
\hline Reducing power & $68.51 \pm 0.001^{\mathrm{d}}$ & $76.07 \pm 0.001^{c}$ & $90.65 \pm 0.001^{\mathrm{b}}$ & $98.79 \pm 0.001^{\mathrm{a}}$ \\
\hline $\begin{array}{l}\beta \text {-carotene bleaching } \\
\text { inhibition }\end{array}$ & $47.89 \pm 0.002^{\mathrm{d}}$ & $184.92 \pm 0.001^{\mathrm{b}}$ & $177.23 \pm 0.004^{\mathrm{c}}$ & $195.10 \pm 0.01^{\mathrm{a}}$ \\
\hline TBARS inhibition & $38.73 \pm 0.001^{\mathrm{b}}$ & $48.63 \pm 0.000^{\mathrm{a}}$ & $15.24 \pm 0.002^{\mathrm{d}}$ & $19.79 \pm 0.003^{c}$ \\
\hline
\end{tabular}

$\mathrm{EC}_{50}$ values correspond to the sample concentration achieving $50 \%$ of antioxidant activity or 0.5 of absorbance in the reducing power assay. In each row different letters mean significant differences with a $P<0.05$. They refer to Tukey's post hoc test; therefore, significant different values were classified using letters in alphabetic order.

\section{Conflict of Interests}

The authors declare that there is no conflict of interests regarding the publication of this paper.

\section{Acknowledgments}

The authors are grateful to Project PRODER n ${ }^{\circ}$ 46577-PlantLact and to Foundation for Science and Technology (FCT,
Portugal) for financial support to the research centre CIMO (PEst-OE/AGR/UI0690/2011) and for L. Barros' contract (Compromisso para a Ciência 2008).

\section{References}

[1] O. P. Borges, J. Soeiro Carvalho, P. Reis Correia, and A. Paula Silva, "Lipid and fatty acid profiles of Castanea sativa Mill. Chestnuts of 17 native Portuguese cultivars," Journal of Food Composition and Analysis, vol. 20, no. 2, pp. 80-89, 2007. 
[2] INE, Instituto Nacional de Estatística. Chestnuts national statistics, 2012, http://www.ine.pt/xportal/xmain?xpid=INE\& xpgid=ine_publicacoes\&PUBLICACOESpub_boui=153380933 \&PUBLICACOESmodo $=2$.

[3] T. K. Lim, Edible Medicinal and Non-Medicinal Plants, vol. 1 of Fruits, Springer, 2012.

[4] Patent CN102524895 B, https://www.google.com/patents/

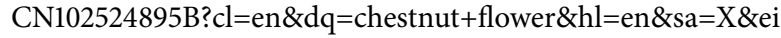
=pmGTUvuJBJKI7AbTqIHABQ\&ved= 0CEAQ6AEwAQ.

[5] Patent CN102334573 B, https://www.google.com/patents/ $\mathrm{CN102334573B}$ ? cl=en\&dq=chestnut+flower\&hl=en\&sa=X\&ei =pmGTUvuJBJKI7AbTqIHABQ\&ved= 0CH8Q6AEwCA.

[6] Patent CN102972838 A, https://http://www.google.com/patents/ $\mathrm{CN102972838A}$ ?cl=en\&dq=chestnut+flower\&hl=en\&sa=X\&ei $=$ pmGTUvuJBJKI7AbTqIHABQ\&ved $=0$ CHYQ6AEwBw.

[7] M. C. B. M. de Vasconcelos, R. N. Bennett, E. A. S. Rosa, and J. V. Ferreira-Cardoso, "Composition of European chestnut (Castanea sativa Mill.) and association with health effects: fresh and processed products," Journal of the Science of Food and Agriculture, vol. 90, no. 10, pp. 1578-1589, 2010.

[8] L. Barros, S. Oliveira, A. M. Carvalho, and I. C. F. R. Ferreira, "In vitro antioxidant properties and characterization in nutrients and phytochemicals of six medicinal plants from the Portuguese folk medicine," Industrial Crops and Products, vol. 32, no. 3, pp. 572-579, 2010.

[9] L. Barros, C. T. Alves, M. Dueñas et al., "Characterization of phenolic compounds in wild medicinal flowers from Portugal by HPLC-DAD-ESI/MS and evaluation of antifungal properties," Industrial Crops and Products, vol. 44, pp. 104-110, 2013.

[10] C. Pereira, L. Barros, A. M. Carvalho, and I. C. F. R. Ferreira, "Use of UFLC-PDA for the analysis of organic acids in thirtyfive species of food and medicinal plants," Food Analytical Methods, vol. 6, pp. 1337-1344, 2013.

[11] L. Day, R. B. Seymour, K. F. Pitts, I. Konczak, and L. Lundin, "Incorporation of functional ingredients into foods," Trends in Food Science and Technology, vol. 20, no. 9, pp. 388-395, 2009.

[12] K. M. Barry, N. W. Davies, and C. L. Mohammed, "Identification of hydrolysable tannins in the reaction zone of Eucalyptus nitens wood by high performance liquid chromatographyelectrospray ionisation mass spectrometry," Phytochemical Analysis, vol. 12, no. 2, pp. 120-127, 2001.

[13] E. Cantos, J. C. Espín, C. López-Bote, L. De la Hoz, J. A. Ordóñez, and F. A. Tomás-Barberán, "Phenolic compounds and fatty acids from acorns (Quercus spp.), the main dietary constituent of free-ranged Iberian pigs," Journal of Agricultural and Food Chemistry, vol. 51, no. 21, pp. 6248-6255, 2003.

[14] A. Romani, M. Campo, and P. Pinelli, "HPLC/DAD/ESI-MS analyses and anti-radical activity of hydrolyzable tannins from different vegetal species," Food Chemistry, vol. 130, no. 1, pp. 214221, 2012.

[15] J.-P. Salminen, V. Ossipov, J. Loponen, E. Haukioja, and K. Pihlaja, "Characterisation of hydrolysable tannins from leaves of Betula pubescens by high-performance liquid chromatographymass spectrometry," Journal of Chromatography A, vol. 864, no. 2, pp. 283-291, 1999.

[16] B. Zywicki, T. Reemtsma, and M. Jekel, "Analysis of commercial vegetable tanning agents by reversed-phase liquid chromatography-electrospray ionization-tandem mass spectrometry and its application to wastewater," Journal of Chromatography A, vol. 970, no. 1-2, pp. 191-200, 2002.

[17] T. J. Hager, L. R. Howard, R. Liyanage, J. O. Lay, and R. L. Prior, "Ellagitannin composition of blackberry as determined by
HPLC-ESI-MS and MALDI-TOF-MS," Journal of Agricultural and Food Chemistry, vol. 56, no. 3, pp. 661-669, 2008.

[18] M. Sanz, E. Cadahía, E. Esteruelas et al., "Phenolic compounds in chestnut (Castanea sativa Mill.) heartwood. Effect of toasting at cooperage," Journal of Agricultural and Food Chemistry, vol. 58, no. 17, pp. 9631-9640, 2010.

[19] K. R. Määttä-Riihinen, A. Kamal-Eldin, and A. R. Törrönen, "Identification and quantification of phenolic compounds in berries of Fragaria and Rubus species (family Rosaceae)," Journal of Agricultural and Food Chemistry, vol. 52, no. 20, pp. 61786187, 2004.

[20] M. D. Bubba, L. Checchini, U. Chiuminatto, S. Doumett, and D. F. E. Giordani, "Liquid chromatographic/electrospray ionization tandem mass spectrometric study of polyphenolic composition of four cultivars of Fragaria vesca L. berries and their comparative evaluation," Journal of Mass Spectrometry, vol. 47, pp. 1207-1220, 2012.

[21] P. Mena, L. Calani, C. Dall'Asta et al., "Rapid and comprehensive evaluation of (poly)phenolic compounds in pomegranate (Punica granatum L.) juice by UHPLC-MS ${ }^{n}$," Molecules, vol. 17, pp. 14821-14840, 2012.

[22] M. Dueñas, H. Mingo-Chornet, J. J. Pérez-Alonso, R. Di PaolaNaranjo, A. M. González-Paramás, and C. Santos-Buelga, "Preparation of quercetin glucuronides and characterization by HPLC-DAD-ESI/MS," European Food Research and Technology, vol. 227, no. 4, pp. 1069-1076, 2008.

[23] D. R. Janero, "Malondialdehyde and thiobarbituric acid-reactivity as diagnostic indices of lipid peroxidation and peroxidative tissue injury," Free Radical Biology and Medicine, vol. 9, no. 6, pp. 515-540, 1990. 

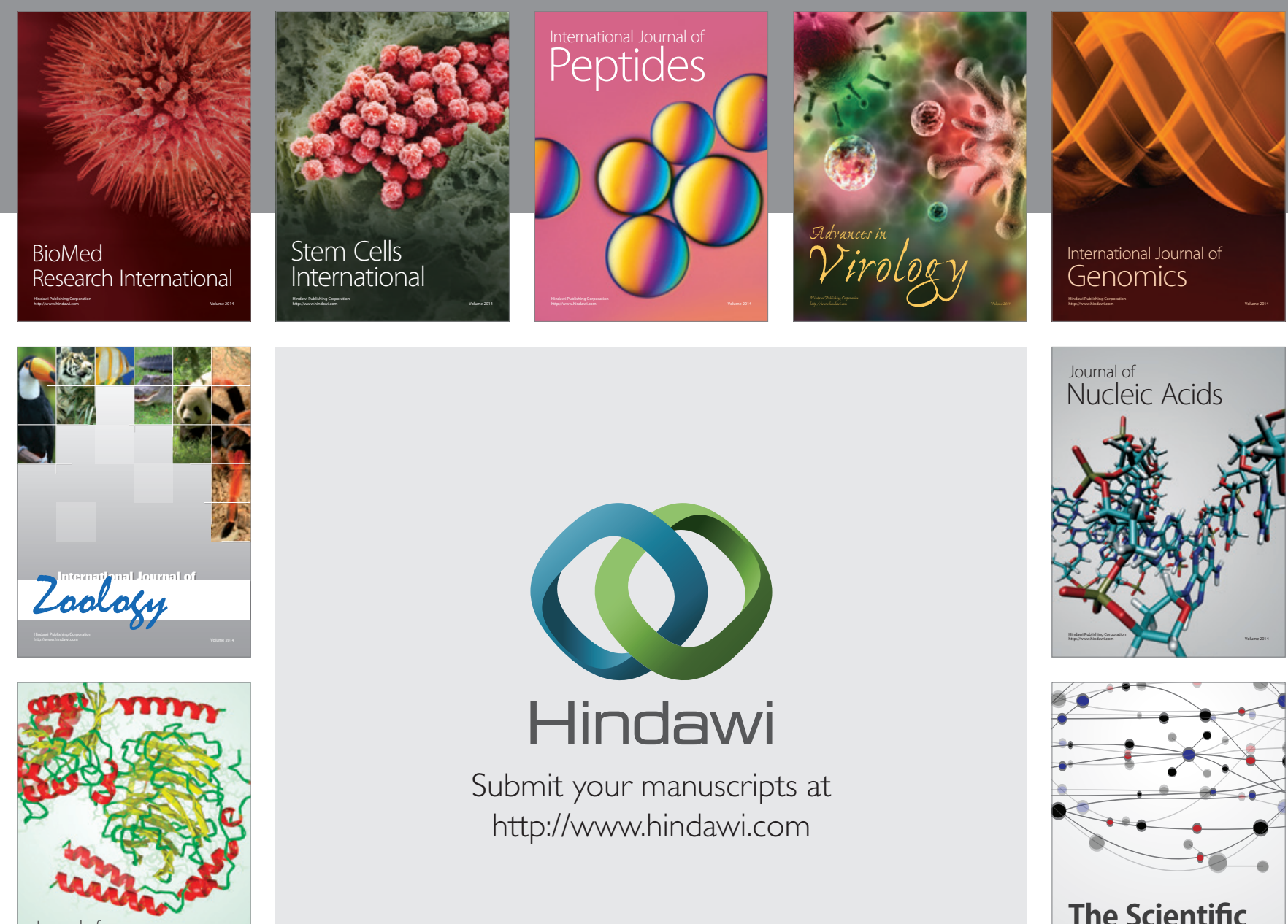

Submit your manuscripts at

http://www.hindawi.com

Journal of
Signal Transduction
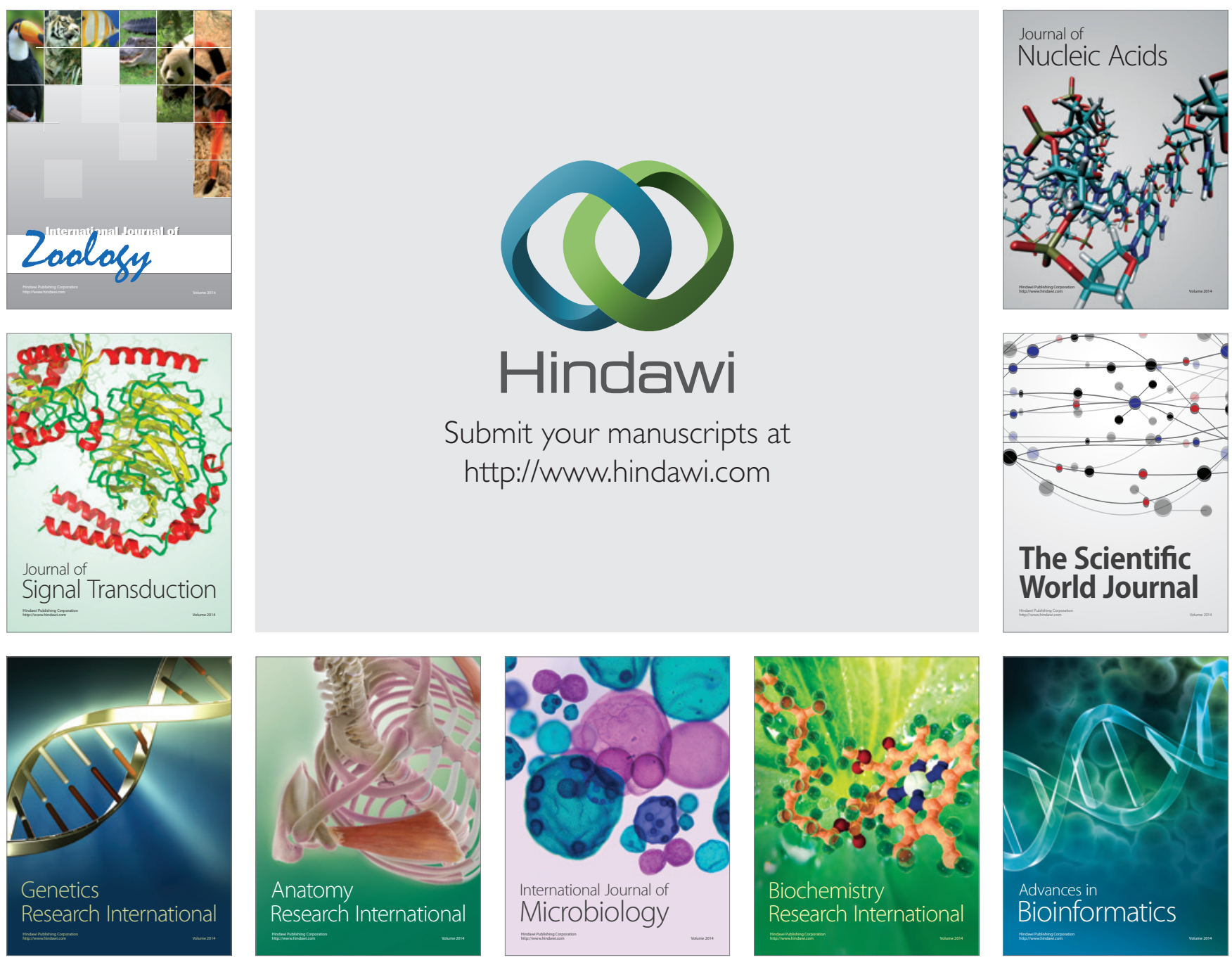

The Scientific World Journal
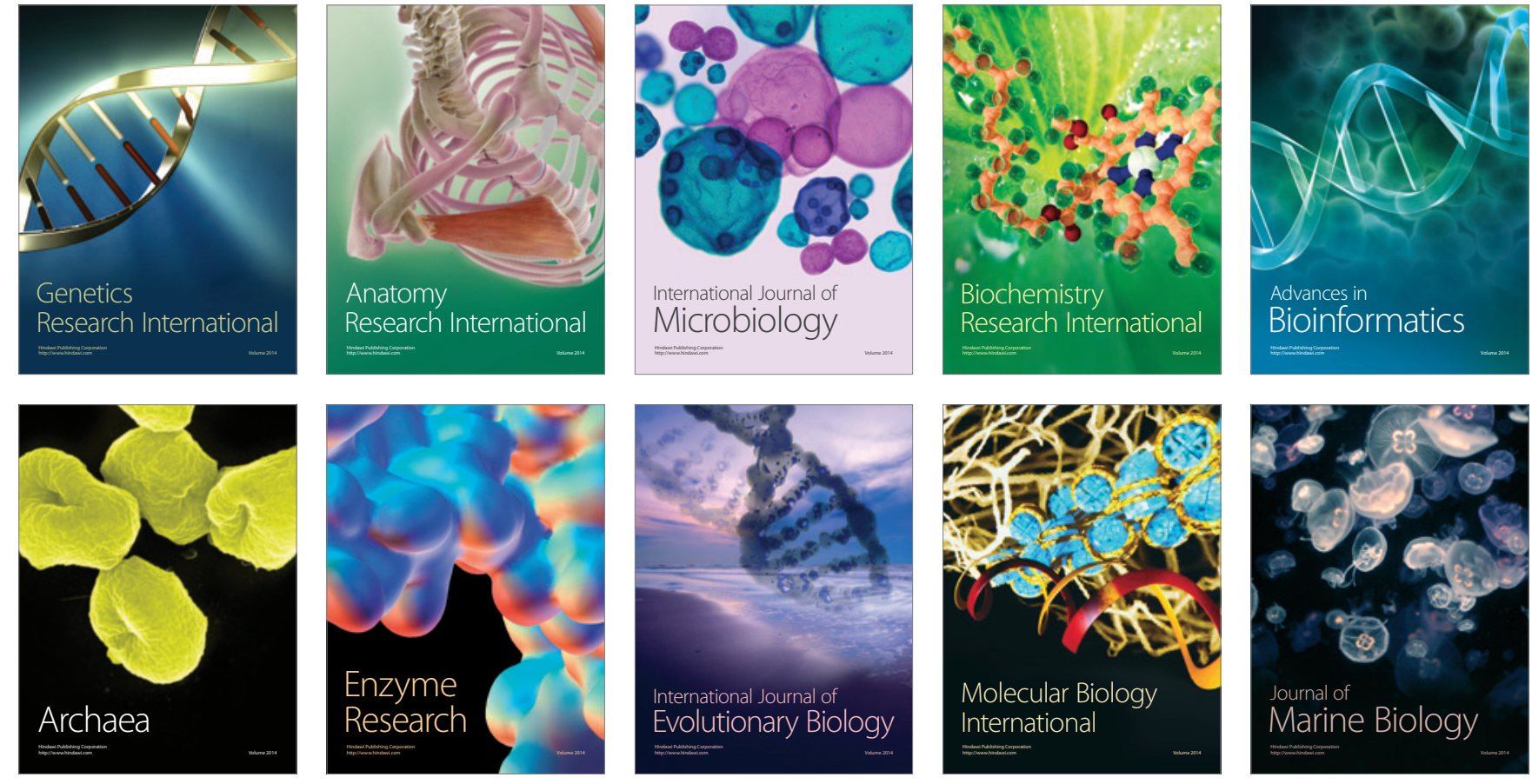